\title{
Cobertura da greve paranaense no Facebook: engajamento dos leitores na página da Gazeta do Povo
}

\section{Strike media coverage on Facebook: reader's engagement on the Gazeta do Povo's fanpage}

\author{
Michele Goulart Massuchin \\ Professora adjunta do Curso de Comunicação Social/Jornalismo da Universidade Federal do Maranhão (UFMA), Doutora em \\ Ciência Política pela Universidade Federal de São Carlos (UFSCar), mestre em Ciência Política pela Universidade Federal do \\ Paraná (UFPR) e graduada em Comunicação Social - Jornalismo pela Universidade Estadual de Ponta Grossa (UEPG). \\ $<$ mimassuchin@gmail.com>
}

\section{Camilla Quesada Tavares}

Doutoranda em Comunicação pela Universidade Federal Fluminense (UFF) e mestre em Ciências Sociais Aplicadas pela Universidade Estadual de Ponta Grossa (UEPG). Professora substituta do Departamento de Jornalismo da UEPG. <camilla.tavares8@gmail.com>

\section{RESUMO}

Este artigo analisa como as notícias sobre a greve dos professores do Paraná, postadas na página do jornal Gazeta do Povo no Facebook, geraram feedback entre os seguidores. O objetivo é identificar, por meio de um estudo de caso, se o tema "greve" foi capaz de mobilizar os leitores e promover maior interação do que nas demais postagens. A hipótese é de que notícias referentes ao assunto em específico geraram maior engajamento entre os leitores, divergindo do comportamento usual dos mesmos em relação ao conteúdo geral publicado cotidianamente na página do veículo no Facebook. A análise é feita tendo como base as postagens $(n=1.691)$ feitas na página da Gazeta do Povo e as diferentes formas de engajamento proporcionadas pelas redes sociais digitais durante o período de 15 de abril e 26 de junho de 2015, que engloba a segunda fase da paralisação que ocorreu no Paraná.

\begin{abstract}
This article examines how the news about the strike of Paraná teachers, posted on the page of the newspaper Gazeta do Povo on Facebook, generated feedback from users who had access to the content. The aim is to identify, through a case study, if the theme "strike" was able to mobilize readers and promote greater interaction than other posts. The hypothesis is that the news concerning the subject generated greater engagement with readers, diverging from the usual behavior of the same in relation to the content published daily in the vehicle's Facebook page. The analysis is based on posts $(n=1691)$ made in the Gazeta do Povo fanpage during the period from April 15th to June 26th, 2015, which includes the second phase of the strike that took place in Paraná and the confrontation between strikers and police on April 29th. The results indicate that the theme strike generates greater online engagement than others.
\end{abstract}

Keywords: Social Networks. Communication. Facebook.

\section{Introdução}

Este artigo tem como objetivo analisar como as notícias sobre a greve 
dos professores do Paraná', postadas na página do jornal Gazeta do Povo no Facebook, geraram feedback entre os usuários que tiveram acesso ao conteúdo. A análise compara a interação dos usuários em relação às notícias que tratam da greve com o comportamento usual que ocorre no restante do conteúdo postado pela Gazeta do Povo. A hipótese central levantada é que o tema pautado devido às suas características fora da internet - define o nível de interação entre leitor e conteúdo e, nesse caso a ser estudado, há diferenças significativas entre o tema "greve" e qualquer outro tipo de postagem feita pelo veículo durante o período analisado na rede social digital estudada. Isso pode ser explicado por se tratar de um assunto local, que atinge diretamente o público-alvo do veículo, majoritariamente do estado do Paraná, e tem implicações amplas na população.

Trata-se de um estudo voltado para entender as dinâmicas do engajamento on-line e do processo de circulação de informação pelas redes sociais e tem-se como ponto de partida que elas são utilizadas como ferramentas de disseminação de conteúdo jornalístico na internet, possibilitando que a informação chegue a várias sub-redes (Recuero, 2009). Ao mesmo tempo, também permitem interação dos usuários, os quais podem comentar, curtir e compartilhar o conteúdo, gerando um novo tipo de comportamento.

A pesquisa parte do pressuposto de que os meios de comunicação que se utilizam de páginas em rede sociais conseguem maior alcance das notícias. $O$ conteúdo que é replicado na página oficial de veículos jornalísticos no Facebook, por exemplo, atinge mesmo aqueles que não possuem necessariamente contato direto com o post produzido, por meio de opções como "curtir" e "compartilhar" chegando ao fenômeno que Aggio e Reis (2015) chamam de ecologia dos fluxos de informação on-line. Além disso, as opções de fazer um comentário, compartilhar e curtir também demonstram o interesse dos leitores quanto a determinado assunto, o que podemos chamar aqui de engajamento on-line, mesmo que seja uma forma um tanto restritiva.

Para desenvolver a análise proposta, foram coletados todos os posts da página da Gazeta do Povo no Facebook ${ }^{2}$, entre os dias 15 de abril a 26 de junho de 2015, o que totalizou um corpus de 1691 unidades. Foram analisados o tema geral, o número de compartilhamento, comentários e curtidas em cada postagem. A pesquisa trabalha com os dados de modo comparado, separando os

1 A greve dos professores da rede estadual do Paraná em 2015 ganhou destaque na imprensa local, nacional e até internacional devido ao período longo da paralisação e dos fatos violentos do dia 29 de abril. Mais informações sobre o contexto do tema analisado será apresentado em um tópico específico, que antecede a análise.

2 A página oficial da Gazeta do Povo no Facebook possuía, em julho de 2015, mais de 410 mil curtidas. 
posts sobre a greve dos servidos dos demais, justamente para tentar identificar as diferenças quanto à interação dos leitores e sua relação com o assunto em questão.

O artigo está dividido da seguinte forma: na primeira parte discute-se o uso das redes sociais pelo jornalismo e, na sequência, as potencialidades da ferramenta quanto a ampliação do debate e engajamento on-line. Depois, apresenta-se o contexto da pesquisa - retomando alguns fatos importantes da greve - e a metodologia de análise para, em seguida, apresentar os dados, usando testes de média para ver se as diferenças no comportamento são significativas ou não. Por fim, faz-se as considerações finais, retomando o debate teórico e enfatizando a discussão sobre a importância do tema como fator para criar ou incitar o engajamento dos leitores por meio das redes sociais digitais.

\section{Jornalismo, redes sociais e circulação de informação}

Com a popularização da internet e, mais recentemente, com o uso constante das redes sociais, o cidadão ganhou novas possibilidades para buscar informação, tornando-se menos dependente da cobertura televisiva ou dos grandes veículos impressos. Na prática, isso significa que os veículos jornalísticos deixaram de ser únicos no processo de consumo (Heinrich, 2011) e transitam, junto com outros espaços on-line, como redes sociais, blogs, fóruns, e-mails e sites de conteúdos variados, na composição do ambiente informacional dos cidadãos (Primo, 2011; Dalmaso, 2012). Segundo Primo (2011), o indivíduo consome toda e qualquer informação que estiver on-line, o que vai muito além dos sites jornalísticos. $\mathrm{O}$ autor nomeia esse cruzamento de informação de "composto informacional midiático" (Primo, 2011), que gera a visão de mundo que cada cidadão terá. No entanto, isso não significa dizer que os veículos informativos perderam sua função, mas, sim, que precisaram se adaptar a essa tendência.

Uma das maneiras de os veículos informativos fazerem isso é por meio da apropriação dos espaços nos sites de rede social. Os jornais impressos passaram a ter os próprios portais na internet, sendo que agora também ocupam as redes sociais. Essa migração para o on-line tem relação com o aumento significativo do uso da internet entre os usuários brasileiros. O tempo gasto nas redes aumentou consideravelmente nos últimos anos. De acordo com a Pesquisa Brasileira de Mídia (PBM, 2014), 48\% dos brasileiros utilizam a internet, sendo que $37 \%$ acessam a rede todos os dias. Dos usuários frequentes, $67 \%$ afirmam que a usam para consumir notícias e se informar. No que concerne às redes sociais, o Facebook aparece como a rede mais utilizada, com $83 \%$ da preferência 
dos brasileiros (Brasil 2014). Segundo survey realizado pelo Pew Research Center (2015) nos Estados Unidos (BARTHEL e outros, 2015) , 63\% dos usuários do Facebook consideram a rede como uma boa fonte de informação.

Com a presença nas redes sociais on-line, uma estratégia adotada pelos jornais para garantir outro espaço de divulgação e circulação da notícia foi criar páginas oficiais em sites como Facebook e Twitter. Dessa maneira, além de garantir maior proximidade com o público devido às ferramentas interativas, podem divulgar conteúdos paralelos ao site e, assim, ampliar o sistema de difusão e circulação de informações (Dalmaso, 2012; Zago, 2012; Zago e Bastos, 2013; Barros e Carreiro, 2015). Nas redes sociais, a atividade do usuário - como curtir e compartilhar - tem um impacto significativo na difusão das notícias de cada jornal (Zago e Bastos, 2013). Essa replicação confere visibilidade às notícias, que passam a receber maior atenção e maior audiência, porque permeiam as sub-redes (Recuero, 2009) e chegam até mesmo àqueles usuários que não estão em contato direto com a publicação.

A divulgação do material do site no Facebook, por exemplo, pode fazer com que alguns temas ganhem destaque e maior visibilidade ao passo que outros podem ser obstruídos (Zago e Bastos, 2013). No caso de jornais ou portais de notícia, nem tudo o que está no site é replicado no Facebook, ou seja, há um filtro que determina o que segue para a rede social. Além disso, as matérias produzidas para o site, e divulgadas posteriormente nas redes sociais, podem agregar informações aprofundadas e proporcionar pluralidade de fontes e visões sobre os acontecimentos, conforme prevê a estrutura do texto para web (Canavilhas, 2006). Ainda nesse sentido, o número de matérias produzidas sobre o mesmo assunto poderia aumentar, já que se trabalharia com essas informações complementares. Dessa forma, nota-se mudanças nos modos de fazer jornalismo na internet, assim como na forma de distribuição da informação agora também pelas redes sociais que contribuem com o processo de circulação de conteúdo (Zago, 2012), antes restritos aos meios tradicionais.

\section{Engajamento on-line e interação pelas redes sociais digitais}

Além de as redes sociais possibilitarem uma nova maneira de circulação e consumo de conteúdos informativos na internet, elas estabelecem novas formas de interação entre jornal e usuário (Teixeira, 2014), assim como é recorrente na relação entre candidatos e eleitores em períodos eleitorais, a partir da interação por meio dessas ferramentas (Aggio, 2010). Barros e Carreiro (2015) argumentam que a rede possibilita ao usuário integrar uma esfera conversacional, seja ela temporal (poder de comentar a notícia enquanto ela ainda é transmitida), 
ou espacial (fazer comentários no mesmo ambiente em que o conteúdo é disseminado). No caso das notícias postadas nas páginas dos jornais no Facebook, essa esfera é bastante visível, já que o leitor tem a possibilidade de comentar, curtir ou compartilhar instantaneamente o conteúdo assim que ele é publicado, interferindo no alcance da informação (Zago, 2012) e indicando, ainda, seu interesse e engajamento quanto ao assunto.

Por meio das ferramentas das redes sociais é possível falar de um novo tipo de engajamento, agora na esfera on-line (Aggio, 2010). O ato de curtir, compartilhar e até mesmo comentar determinada postagem de notícia indica, ao menos, um interesse prévio, podendo ser comparado a uma pseudomobilização (Klotz, 2007). Entende-se por engajamento aqui o ato de colaborar ou empenhar-se em determinado tema ou questão utilizando as ferramentas das redes sociais. Essas possibilidades oferecidas podem ou não ser "acatadas" pelos usuários de internet que acessam as notícias pelo Facebook e isso depende do modo como ele pretende interagir com o conteúdo, ou engajarse nele. Embora essa mídia tenha características estruturais que permitam a interação e participação, conforme lembram Barros e Carreiro (2015), ela não leva automaticamente ao engajamento cívico (Ferreira e Alves, 2014). É preciso que eles se sintam instigados para interagirem com o conteúdo por meio desses mecanismos, sendo que isso pode variar conforme o tema, a intensidade das mobilizações no mundo off-line, a proximidade, o impacto social, entre outros fatores.

Numa perspectiva mais abrangente dos estudos sobre internet e participação política, para a vertente deliberacionista, a internet possibilitaria uma arena fértil para o engajamento e, inclusive, de deliberação por parte dos cidadãos. Dentre as suas atribuições estariam a de gerar novas modalidades de interação, ampliar o estoque de informação acessível e o de fomentar o debate público (Mendonça e Pereira, 2011). No entanto, Marques (2006) ressalta que viabilizar o debate não garante que todos queiram discutir, tampouco que se dediquem a chegar a algum consenso sobre determinados assuntos. Em termos de redes sociais, pode ser que o leitor não queira curtir, compartilhar e nem falar de determinado assunto. Sampaio e Barros (2010) já indicaram, ao estudar a deliberação em espaços de comentários em portais de notícia, que o tema é uma variável importante para gerar mais ou menos debate. Neste texto, pretende-se observar, de modo similar, se o tema é importante para definir maior ou menor interação entre os leitores e as postagens feitas no Facebook, mas observando não apenas o número de comentários, mas também as possibilidades de compartilhamento e curtidas. 
A associação defendida aqui é entre as possibilidades interativas das redes sociais - curtir, compartilhar e comentar - e como isso pode ser considerado como características de engajamento quando se trata de publicações de notícias, considerando o interesse dos seguidores. Trata-se, obviamente de níveis diferentes de se interessar por determinado assunto, sendo que uma "curtida" desprende menos esforço do que o engajamento por meio do debate on-line através dos comentários, por exemplo. No entanto, não deixa de ser uma forma de interação com o conteúdo que, na hipótese deste artigo, tem relação intrínseca com o tema. Ou seja, a opção ou não por essas ações de engajamento depende do tema ou assunto, tendo um valor social relevante quando se trata de assunto de interesse público, tal qual se pretende analisar neste texto. Portanto, nem sempre o leitor estaria disposto a interagir com o conteúdo e contribuir com a circulação da informação.

A conversação que se estabelece na rede - podendo ser por meio de comentários - é ainda importante para que se amplie o entendimento que os participantes têm sobre determinado assunto, segundo Maia (2001). Assim, é possível compartilhar pontos de vista (Zuñiga e outros, 2010) sobre os temas que ganham visibilidade na mídia, sendo que as posições dos atores são publicizadas a partir da interação - que colabora para a disseminação da notícia e com a conexão do interesse da rede de amigos com um tema público (Barros e Carreiro, 2015). Montardo e Araújo (2013) indicam ainda que, por possuir caráter mais horizontal de comunicação, as redes garantem visibilidade às mobilizações nas quais se engajam um número relevante de indivíduos.

Ferreira e Alves (2014) reiteram que o Facebook tem se mostrado uma plataforma potencial para promover encontros, desenvolver debates e criar laços, para além da divulgação de informações, o que corrobora com a ideia de engajamento por meio de redes sociais a diferentes temas. Este estudo trabalha com a hipótese de que esses laços e debates não ocorrem de modo idêntico e estável para com todos os assuntos: há temas que geram mais engajamento que outros. A presença de leitores ou de ferramentas não leva, automaticamente, à interação. Isso vai ocorrer, como se defende na hipótese de pesquisa, quando o tema gerar interesse devido às suas características. $O$ "nível de engajamento" seria diferente entre o assunto estudado - greve - e os demais destaques publicados pelos jornais no Facebook.

Não se trata de uma participação dos leitores, na perspectiva literal das teorias da democracia, mas de mecanismos que podem indicar o quanto as pessoas tendem a se envolver com determinado assunto, empenhandose na mobilização, circulação da informação, proliferação do tema ou debate. 
Os estudos têm voltado suas análises para o engajamento e potenciais de mobilização da rede em campanhas eleitorais (Aggio, 2010), sendo que o objetivo deste artigo é discutir esses mesmos conceitos, mas não atrelado à perspectiva de campanha, e, sim, de temas quaisquer que, dependendo de suas características, também geram interesse e possibilitam a interação, quando aparecem nas redes sociais por intermédio dos veículos de comunicação.

Portanto, parte-se do pressuposto de que é necessário algum tipo de incentivo para que as pessoas se engajem na rede, principalmente para interagir com o conteúdo jornalístico. Não são todos que chamam a atenção, tal como se argumenta. É preciso um assunto em comum, de destaque fora do mundo on-line, que esteja no debate. Assim, acredita-se que a greve dos professores e servidores do Paraná - e seus desdobramentos - deve gerar maior engajamento e mobilização do que os demais assuntos, que são recorrentes à opinião pública, mas que pouco são atrativos do ponto de vista de um empenho do público que gere, posteriormente, mobilização por meio das redes sociais. Para se conhecer os caminhos metodológicos adotados nesta pesquisa, bem como o contexto do qual estamos nos referindo, apresentamos o tópico a seguir.

\section{Desenho da pesquisa e contexto de análise}

Os dados referentes a esta pesquisa foram coletados a partir do aplicativo Netvizz ${ }^{3}$ e correspondem ao período do dia 15 de abril a 26 de junho de 2015. O recorte considera todo o período da segunda paralisação realizada pelos docentes do Paraná, a qual teve início no dia 23 de abril e terminou somente no dia 25 de junho. O período agrega, ainda, uma semana anterior ao dia 23 de abril, já que o assunto estava bastante presente no debate público, e também o dia seguinte da decisão pelo fim da paralisação. Ao todo, foram publicadas na página da Gazeta do Povo 1.691 postagens, replicando o conteúdo noticioso do portal do veículo, sendo que 132 correspondiam à temática da paralisação dos docentes e servidores.

Neste artigo, o objetivo é identificar as diferenças no que diz respeito à interação por meio das ferramentas do Facebook explicar os diferentes níveis de engajamento do público. Para tanto, compara-se as postagens sobre a greve $(n=132)$ com aquelas referentes aos demais assuntos replicados na rede

3 O Netvizz é um aplicativo disponibilizado pelo próprio Facebook que permite a captação das postagens de páginas públicas. O aplicativo permite fazer o download a partir de uma quantidade de posts específica ou por delimitação do período de tempo. No caso deste estudo, optou-se pela segunda opção. Um banco de dados com todas as informações é criado e a categorização dos posts é feita a partir dessa planilha. 
social, analisando o número de compartilhamentos, comentários, curtidas e os temas específicos categorizados a partir de um livro de codificação, produzido previamente para a análise de conteúdo ${ }^{4}$.

Complementar à primeira hipótese já discutida ao longo da discussão teórica, a segunda proposição afirma que dentre os assuntos específicos dos posts sobre greve (confronto, votações, manifestações e efeitos sociais da paralisação), também há diferenças na maneira como as pessoas interagem, sendo que alguns grupos tendem a gerar maior engajamento e interesse que outros, como é o caso do subtema "confronto", em que as postagens gerariam maior quantidade de comentários em função do contexto político e da violência dos atos do dia 29 de abril, que geraram mobilização, tanto on-line como offline. Para testar tais hipóteses e as distinções referidas, são feitos testes de diferença de média, tais como o teste T e ANOVA ${ }^{5}$. Por ser um estudo de caso, não se pode fazer generalizações dos resultados para outros cenários. Porém, a partir da discussão teórica e empírica é possível ampliar o debate que relaciona jornalismo, engajamento e público nas redes sociais.

Em termos de contextualização do período e do tema analisado é necessário fazer algumas ponderações sobre o movimento grevista. A greve dos professores da rede estadual do Paraná de 2015 foi dividida em dois períodos: começou no dia nove de fevereiro e tinha como principal ponto de reivindicação a retirada do projeto de lei que autorizava o governo a sacar dinheiro da Paraná Previdência e a mudar o sistema da aposentadoria. Com a retirada da proposta da Assembleia Legislativa do Paraná (Alep) e uma "carta de compromisso", a paralisação foi suspensa e as aulas foram retomadas em meados de março. No entanto, após o governo descumprir um dos itens estabelecidos na carta de compromisso, a segunda etapa da greve iniciou-se no dia 27 de abril. 0 projeto foi à votação na Alep no dia 29 de abril, dia em que ocorreu o enfrentamento entre a política e os manifestantes, o qual ficou conhecido como "massacre". O projeto foi aprovado e sancionado pelo governador no dia seguinte. No início de maio, começou o debate sobre a data-base, já que o governo não garantiu a reposição inflacionária do período 2014/2015, que ficou em 8,17\%. As negociações seguiram pelos meses de maio e junho. No dia nove de junho, os servidores da rede básica de ensino, ligados ao Sindicato dos Trabalhadores em Educação Pública do Paraná (APP Sindicato), decidiram aceitar a proposta do Executivo e encerraram a greve. Já os professores e servidores do ensino

4 Uma versão contendo a análise dos conteúdos das notícias replicadas no Facebook foi publicada na coletânea Coberturas jornalísticas (de)marcadas: a greve dos professores na mídia paranaense, em 2015.

5 Os testes foram feitos com o auxílio do pacote estatístico SPSS. 
superior mantiveram a paralisação. Apesar dos esforços, o projeto foi aprovado no dia 16 de junho. Nos dias seguintes, os sindicatos de várias universidades convocaram assembleia docente para avaliar a situação e, embora não se tenha conseguido avanços na pauta de reivindicação, os docentes votaram pelo fim da greve que foi suspensa no dia 25 daquele mês.

\section{Engajamento no Facebook: compartilhamento, comentários e curtidas}

O primeiro dado a ser destacado é que durante as oito semanas de análise - 15 de abril a 27 de junho - do total de 1.691 postagens feitas pela Gazeta do Povo no Facebook, 8,4\% do total diziam respeito à greve dos professores. Portanto, de cada 10 posts, um deles se referia ao tema em análise, o que resultou em 132 entradas somente sobre a greve dos servidores. Destaca-se que as postagens apresentam um link que direciona o leitor ao portal da Gazeta do Povo, sendo que o post do Facebook, na maior parte dos casos, apresentava uma foto, seguido de uma breve chamada sobre o assunto e o link. Dessa forma, caso o leitor se interessasse pelo tema, seria direcionado ao site para a leitura da notícia completa ${ }^{6}$. Isso já mostra um intercâmbio entre as redes sociais e os portais com conteúdo no formato mais tradicional de notícias.

A análise proposta é comparativa, dividindo em dois grupos as postagens durante o período estudado. De um lado, textos sobre a greve e, de outro, assuntos que não dizem respeito ao fato e poderiam ter qualquer abrangência ou abordagem, seja voltado ao interesse público ou não. O objetivo aqui é isolar as notícias sobre a greve replicadas no Facebook e observar se o nível de interação dos leitores difere, tendo em conta que a greve era um assunto de proximidade com os leitores do jornal. Portanto, ao longo da análise, os dados estão divididos e observa-se, como segue na tabela 1, a média e o desvio padrão da quantidade de curtidas, comentários e compartilhamentos gerados nas notícias que tratam da greve e daquelas que dizem respeito às demais postagens.

\section{- Tabela 1 - Comparativo sobre curtidas, comentários e compartilhamentos}

6 Outra informação importante para ser destacada é que embora a análise tenha sido feita considerando 1.691 postagens, algumas delas remetiam para a mesma notícia. Portanto, embora a informação da postagem fosse diferente, o link da notícia era o mesmo. O que significa que não foram exatamente o número de 132 notícias replicadas na rede social, mas um número menor devido aos casos de repetição de link. Isso aconteceu com bastante frequência, por exemplo, no dia 29 de abril, data do confronto, em que a cobertura sobre a greve, ainda que parecesse contínua pelo Facebook, não tinha o mesmo ritmo no Portal da Gazeta do Povo. Além disso, como neste caso a análise referia-se ao conteúdo do post, em determinados casos havia divergência entre o conteúdo/abordagem dado ao post e ao conteúdo da notícia replicada. 


\begin{tabular}{|l|l|r|r|r|}
\hline \multirow{2}{*}{ Likes } & GREVE & $\mathrm{N}$ & \multicolumn{1}{c|}{ Média } & \multicolumn{1}{c|}{ Desvio Padrão } \\
\hline \multirow{2}{*}{ Comentários } & Não & 1.559 & 848,87 & $1.922,157$ \\
\cline { 2 - 5 } & Sim & 132 & $\mathbf{1 . 7 7 3 , 3 9}$ & $2.499,102$ \\
\hline \multirow{2}{*}{ Compartilhamentos } & Não & 1.559 & 86,60 & 169,143 \\
\cline { 2 - 5 } & Sim & 132 & $\mathbf{3 0 8 , 6 2}$ & 382,350 \\
\cline { 2 - 5 } & Não & 1.559 & 227,94 & 615,229 \\
\cline { 2 - 5 } & Sim & 132 & $\mathbf{1 . 6 4 1 , 7 2}$ & $\mathbf{6 . 5 2 8 , 0 6 5}$ \\
\hline
\end{tabular}

Fonte: Autoras (2015)

Esses primeiros dados, comparando a média das distintas formas de interação com o conteúdo, já indicam diferenças importantes entre os textos que tratam da greve em relação àqueles sobre os demais temas replicados no Facebook da Gazeta do Povo. Todas as médias - tanto de curtidas, comentários ou compartilhamentos, são maiores para as notícias referentes à greve. A postagem "No Paraná, 17 policiais se recusam a fazer cerco a professores e são presos", por exemplo, teve 8.099 compartilhamentos. Da mesma forma, a notícia "Base governista ignora batalha campal e aprova lei da previdência" obteve 3.497 comentários na rede social.

Nota-se ainda que embora as médias das notícias sobre a greve - para os três quesitos analisados - são bem superiores, a maior diferença está no caso dos compartilhamentos, com uma média de 1.641 para as notícias referentes à paralisação, contra 227 para aquelas que são referentes a outros temas no mesmo período, o que revela um valor sete vezes maior. Deve-se salientar aqui que o compartilhamento também faz parte de um fenômeno de ampliação do alcance das notícias, o que indica que as notícias da greve tiveram um amplo alcance, inclusive muito maior do que apenas entre os seguidores, com ressalta Recuero (2009) e Zago e Bastos (2013). A proposta dos leitores era fazer com que a notícia tivesse sua circulação ampliada para as redes de amigos (Zago, 2012).

Além disso, nas postagens sobre a greve também se identificou alto grau de debate - considerado como uma das possibilidades da rede por Ferreira e Alves (2014) - muito mais significativo do que nas postagens de outros temas, com uma média quase quatro vezes maior, passando de 86 para 308 comentários de média. $O$ resultado indica que os leitores procuraram formar arenas conversacionais a partir da exposição de suas opiniões sobre o assunto específico da greve (Marques, 2006) e inclusive pode-se retomar a ideia de que por ser um tema extremamente polêmico para o momento houve mais debate 
(Sampaio e Barros, 2010), ainda que não se saiba, com esta análise, o teor do processo deliberativo.

Por outro lado, é preciso considerar que, apesar das grandes diferenças entre as médias, há um alto desvio padrão tanto para compartilhamentos, comentários ou curtidas quando se observa as notícias sobre a greve. O desvio padrão aqui é maior do que para os demais temas nos três tipos de interação. Isso indica que, mesmo entre as postagens somente sobre a greve, há algumas com alto número de comentários e outras com poucos comentários. Pode-se usar como exemplo os casos da postagem do dia 29 de abril, falando sobre o número de feridos no confronto entre professores e policiais no Centro Cívico, que teve 1.307 comentários; e do post que trata sobre o total de dias de paralisação dos servidores, que obteve apenas um comentário.

Esses dados indicam para duas considerações importantes já de início. A primeira diz respeito à média mais elevada para os três quesitos de interação observados nas postagens referentes à paralisação em relação àquelas sobre outros assuntos, o que leva a crer que o tema chamou a atenção dos usuários da rede social, instigando-os para curtir, compartilhar e comentar, sendo este último o mais exigente em termos de esforço desprendido, já que o indivíduo precisa estar disposto a introduzir sua própria opinião e compartilhá-la com os demais participantes do debate (Zúñiga, 2010). Por outro lado, o compartilhamento permite maior abrangência do tema, onde os leitores contribuem com a distribuição de informações sobre o assunto, o que vai ao encontro do que Zago e Bastos (2013) defendem, pois acreditam que a atividade do usuário tem um impacto significativo na propagação desses conteúdos. Mas, além disso, é preciso notar que há grande variação na quantidade de comentários, o que demonstra que nem toda informação sobre a paralisação interessava e gerava maior engajamento, o que tem a ver com postagens menos atrativas e menos instigantes em relação às outras em que havia conflito/confronto.

Para reduzir essas inconsistências, apresenta-se os gráficos boxplot, que indicam a amplitude da variação dentro dos quartis, assim como o valor da mediana, que não sofre interferência de casos isolados, diferente da média. Os gráficos analisados na sequência trazem a relação entre a quantidade de comentários, compartilhamentos e curtidas, também dividindo entre postagens sobre a greve e outros temas replicados na rede social analisada. A diferença é que por meio deles pode-se observar o valor da mediana e a distribuição dos casos, o que salienta a diferença no engajamento quando as postagens se referem à greve, corroborando com a confirmação da hipótese inicial e 
ampliando as discussões sobre a importância de temas para fomentar o debate em locais onde não há outro tipo de incentivo claro (Sampaio e Barros, 2010).

O boxplot a seguir mostra a variação na quantidade de curtidas referentes às postagens sobre a greve e outros temas e suas respectivas medianas. 0 gráfico do boxplot é dividido em quatro partes e cada uma apresenta $25 \%$ dos casos envolvidos, excluindo-se os outliers, sendo que a linha que corta a caixa representa o valor da mediana, ou seja, representa até ela ou acima dela 50\% dos casos. O tamanho do gráfico indica quão homogênea é a distribuição de curtidas nos textos, seja sobre a greve ou outros temas. O primeiro dado, como se pode ver, é que a mediana dos comentários refente às postagens sobre a paralisação é de 835 , sendo que dos demais textos é de 311. Portanto, metade das postagens gerais tem menos de 311 curtidas, sendo que no caso da greve a metade chega até 835 curtidas.

- Gráfico 1 - Quantidade de curtidas nas postagens da Gazeta7

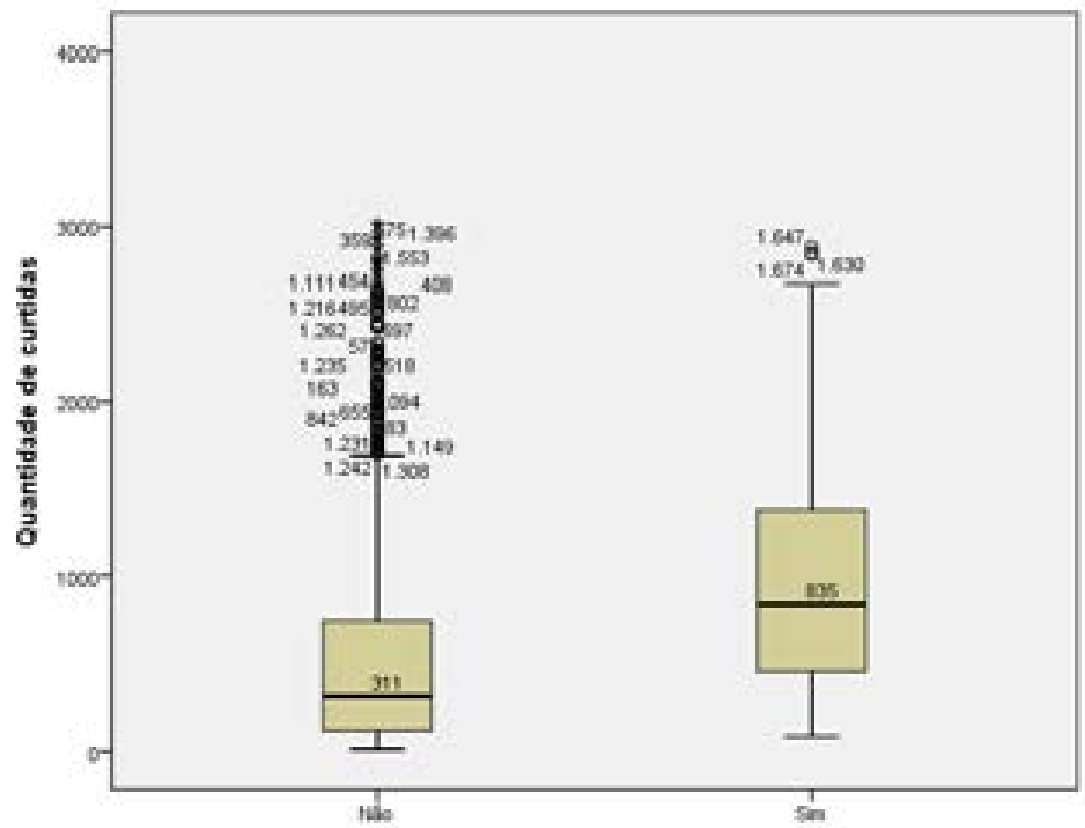

Fonte: Autoras (2015)

Nota-se, ainda, que as postagens gerais possuem maior homogeneidade quanto a quantidade de curtidas, concentrando principalmente nos dois primeiros quadrantes, diferente do caso das notícias sobre a greve, as quais têm

7 O gráfico mostra apenas as postagens que apresentam menos de quatro mil curtidas, excluindo-se assim grande parte dos outliers que se encontram entre 37.383 curtidas e quatro mil curtidas (57 casos). 
maior heterogeneidade, com textos muito pouco curtidos e outros que chegam a quase três mil curtidas. Ainda que ambos se aproximem no que diz respeito à baixa quantidade - com algumas postagens com muito poucas curtidas em ambos os casos - a diferença está no fato de que o gráfico referente à greve agrupa textos com quantidades de curtidas muito maiores do que aqueles que dizem respeito a outros temas. Como as curtidas também ajudam no processo de circulação de conteúdo, nota-se maior distribuição nas redes sociais deste tema.

Comportamento semelhante é percebido quando se trata da quantidade de comentários nas postagens referentes à greve. O tamanho dos gráficos é bastante diferente, o que demonstra que as notícias sobre outros temas tendem a concentrar os comentários até 200 , com um boxplot bastante concentrado, com hastes e caixas pequenas. Já nos textos sobre a greve o boxplot é bem mais extenso, demonstrando heterogeneidade, com postagens de até 600 comentários, ainda que tenham algumas também com poucos. Como já foi dito, também há casos pouco emblemáticos dentro da própria temática greve. Comparando os dois gráficos, nota-se como praticamente metade das notícias sobre a greve apresentam mais comentários em relação àquelas sobre outros assuntos. $O$ debate sobre a greve foi muito maior do que sobre outros temas no período, evidenciando a possibilidade da internet para postar opinião (Marques, 2006). Inclusive, enquanto nas matérias sobre a greve não foram identificados posts sem algum comentário, dentre aquelas com outra temática apareceram 50 postagens que não apresentaram nenhuma publicação por parte do leitor, como é o caso de uma matéria sobre a contratação de empregadas domésticas.

- Gráfico 2 -Quantidade de comentários nas postagens da Gazeta ${ }^{8}$

8 O gráfico mostra apenas as postagens que apresentam menos de 800 comentários, excluindo-se grande parte dos outliers que possuem entre 3.497 comentários até 800 comentários (23 casos). 


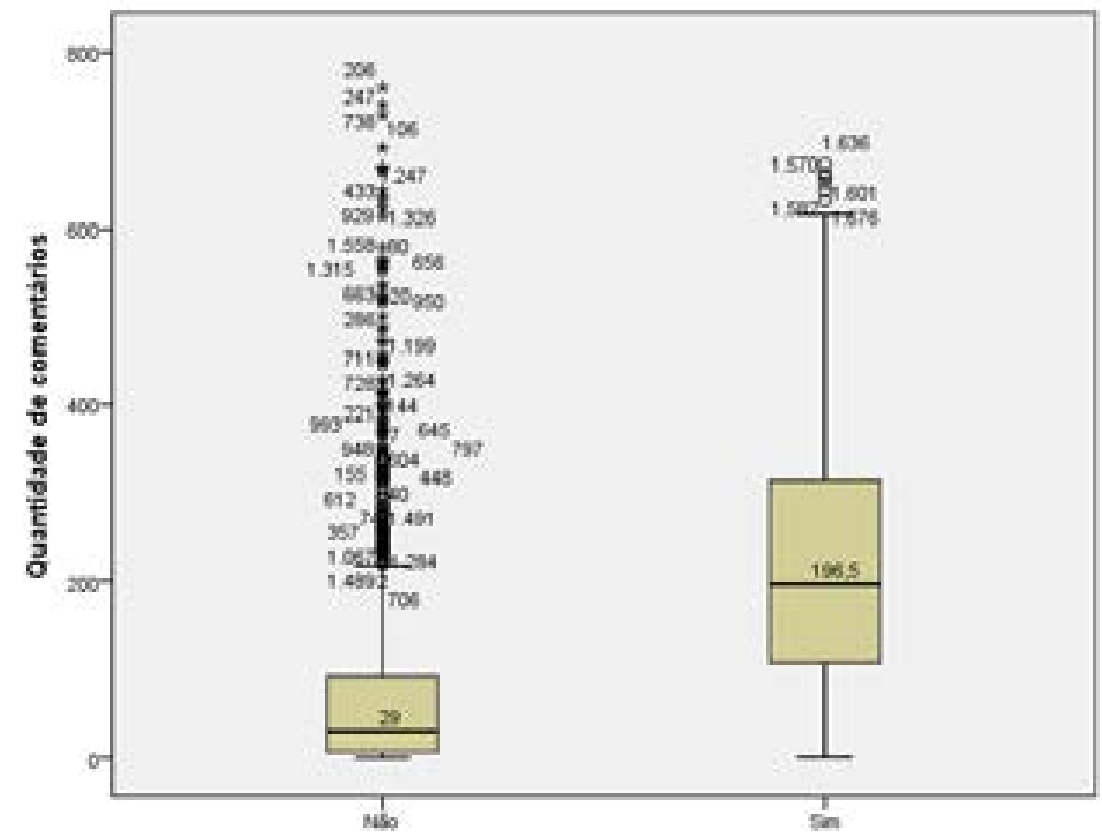

Fonte: Autoras (2015)

Além da heterogeneidade percebida pelo tamanho do gráfico em relação ao outro, a mediana dos comentários das postagens sobre a greve é de 196,5 contra 29 daquelas referentes a outros assuntos. Enquanto metade dos textos sobre a greve chega até quase 200 comentários, no caso dos demais, metade das postagens não alcançaram mais de 30 comentários. Isso indica um debate muito mais expressivo sobre a greve do que outros assuntos, evidenciando a confirmação da hipotese inicial. $O$ tipo de assunto das postagens e sua importância diante dos seguidores da página interfere na intensidade do debate, lembrando a proximidade, a implicação social e outros valores-notícias imbricados nos textos que se referiam à greve.

O compartilhamento é outra forma do leitor demonstrar interesse pelo tema das postagens e, ao mesmo tempo, contribuir com a ampliação de acesso à informação por outros leitores, revigoando a idea das redes como amplificadoras de conteúdo (Dalmaso, 2012). O gráfico seguinte mostra que a intensidade de compartilhamento em notícias sobre a paralisação foi muito maior do que nos demais temas replicados no Facebook. Esse interesse também tem relação com a proximidade do tema com os leitores já que a greve causava impacto direto a muitos paranaenses e envolvia o Governo Estadual e o Legislativo, ganhando destaque no debate público, o que também se traduz nas redes sociais com a interação com as postagens. 


\section{Gráfico 3 - Quantidade de compartilhamentos nas postagens ${ }^{9}$}

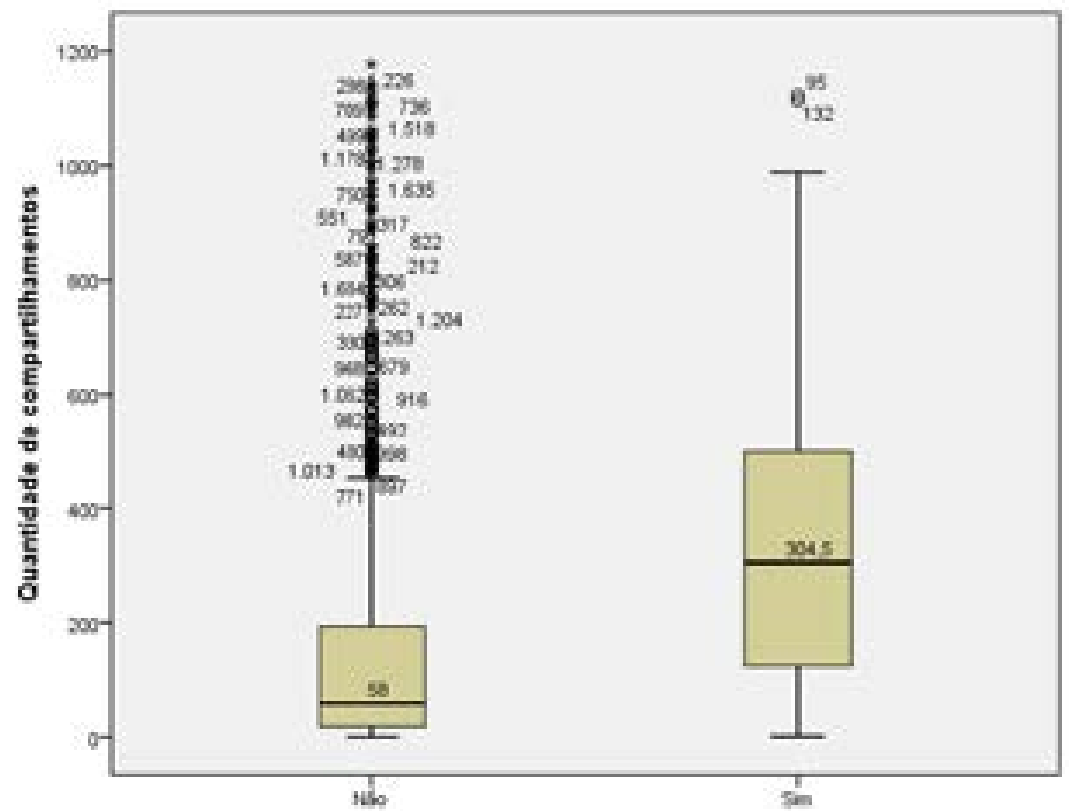

Fonte: Autoras (2015)

A comparação entre postagens sobre a greve com outros temas ressalta que, embora ambos tenham textos com poucos compartilhamentos, os quais não ganharam tanto destaque e interesse, no caso dos textos sobre a greve há maior distribuição com posts com até mil compartilhamentos. Já no caso dos textos sobre outros assuntos replicados no Facebook do jornal, a concentração fica evidente com até pouco mais de 400 compartilhamentos. Quando se observa o tamanho das hastes e caixas, $25 \%$ das postagens sobre a greve têm mais compartilhamentos do que aqueles sobre outros temas, os quais são representados pela haste superior.

Comparando as medianas, no caso das postagens sobre a greve chega a 304,5 compartilhamentos enquanto sobre outros temas não passa de 58 . Esse dado enfatiza que o tema "greve" chama mais a atenção e foi mais replicado por meio das redes sociais do que outros assuntos, alcançando a um público maior que não necessariamente curte a página do jornal no Facebook (Aggio e Reis, 2015), mas recebeu o conteúdo pela prática de compartilhamento de amigos, chegando então às sub-redes (Recuero, 2009). De modo comparado,

9 O gráfico mostra apenas as postagens que apresentam menos de 1100 compartilhamentos, excluindo-se grande parte dos outliers que possuem entre 67846 compartilhamentos até 1100 (50 casos). 
observando os três tipos de práticas interativas proporcionadas pelas redes sociais, nota-se que quanto maior a exigência, menor é o nível de participação, com menor mediana para comentários e maior para curtidas. No caso das redes sociais, fica evidente que quanto menor a exigência, maior o engajamento que requer menos esforços, tempo e contato contínuo. No gráfico seguinte tem-se a soma de todas as formas de interação com o conteúdo, também divididas entre temas referente à paralisação e posts sobre outros assuntos.

Os dados apresentados aqui reafirmam a ideia de que o tema interfere na quantidade de interação dos leitores, enfatizando a hipótese apresentada, pelo menos no que diz respeito a assuntos polêmicos. Neste caso, um dos motivos levantados - que já aparecem na literatura - pode ser pela natureza da temática, que tende a não ser consenso entre os cidadãos. Conforme identificaram Barros e Carreiro (2015), temas onde a posição das pessoas não é homogênea tendem a ser mais debatidos do que aqueles onde há um consenso, justamente pela necessidade de expor sua opinião individual e, quem sabe, convencer a outra pessoa.

Para testar se as diferenças são realmente significativas ao nível de confiança de $95 \%$, fez-se o teste $\mathrm{T}$ de médias, comparando as médias para curtidas, compartilhamentos e comentários entre postagens sobre greve ou outros temas (variável binária). Os dados que seguem na tabela abaixo mostram que é possível estabelecer a hipótese alternativa, de que há diferenças entre as médias, e pode-se refutar a hipótese nula de que a distribuição dos comentários, curtidas e compartilhamentos ocorre de maneira semelhante em todas as postagens ${ }^{10}$.

Tabela 2 - Teste T de independência de médias para comparar os dois grupos

\begin{tabular}{|c|c|c|c|c|c|c|c|}
\hline & & & & & \multicolumn{2}{|c|}{$\begin{array}{c}95 \% \text { de Intervalo de } \\
\text { Confiança }\end{array}$} \\
\cline { 5 - 7 } & & T & Sig. & Diferença de & $\begin{array}{c}\text { Diferença } \\
\text { do Erro } \\
\text { (2-tailed) }\end{array}$ & $\begin{array}{c}\text { Valor } \\
\text { Média }\end{array}$ & $\begin{array}{c}\text { Valos Máxi- } \\
\text { Padrão }\end{array}$ \\
\hline
\end{tabular}

10 Em relação às médias, ver a tabela 1 do artigo. 


\begin{tabular}{|l|r|r|r|r|r|r|r|}
\hline Curtidas & $-5,169$ & 1689 &, 000 & $-924,513$ & 178,845 & $-1275,295$ & $-573,731$ \\
\hline Comentários & $-12,610$ & 1689 &, 000 & $-222,025$ & 17,608 & $-256,560$ & $-187,490$ \\
\hline $\begin{array}{l}\text { Compartilha- } \\
\text { mentos }\end{array}$ & $-8,158$ & 1689 &, 000 & $-1413,776$ & 173,290 & $-1753,661$ & $-1073,890$ \\
\hline $\begin{array}{l}\text { Engajamento } \\
\text { - total }\end{array}$ & $-9,323$ & 1689 &, 000 & $-3124,254$ & 335,101 & $-3781,512$ & $-2466,997$ \\
\hline
\end{tabular}

Fonte: Autoras (2015)

Aqui fica evidente que em temas polêmicos e de proximidade os leitores são mais engajados nas redes sociais tanto no formato mais simples, de curtir, quanto de comentar, que exige maior interesse e disposição. As diferenças são altamente significativas, com sig. de 0.000 para os três casos e, também, para o engajamento que representa o conjunto de interações, confirmando a partir do teste estatístico a diferença no processo de interação, valorizado quanto o tema é a greve. Esse achado corrobora com a ideia de Sampaio e Barros (2010), ainda que os autores se referissem apenas ao processo de debate por meio de comentários. Essa confirmação também leva a conclusão de que o tema greve circulou mais na esfera pública digital, contribuindo com os estudos sobre circularidade de conteúdo por meio das redes sociais digitais (Dalmaso, 2012; Zago, 2012; Zago e Bastos, 2013).

No entanto, dentro do tema "greve", os temas das postagens $(n=132)$ também eram bastante diferentes na cobertura, sendo que foram divididos entre negociações, confronto, manifestação, votações, efeitos sociais da greve e outro ${ }^{11}$. A tabela que segue indica a quantidade de posts relacionados a cada tema, a média de comentários, compartilhamentos e curtidas de cada um, o desvio padrão e os valores mínimo e máximo. Nota-se que no que se refere aos comentários a variação é bastante significativa em todos os temas. $\mathrm{O}$ maior número de comentários, assim como a média, se deu para as postagens sobre o confronto, chegando até 3.497 comentários. A menor média de comentários se deu nos textos sobre as votações, onde o máximo não passou de 673. Isso indica algumas variações quanto ao maior ou menor interesse dos leitores.

11 No subtema "negociações" foram classificadas as matérias que tratavam sobre as etapas de negociação da reposição inflacionária entre governo e sindicatos; em "confronto" entraram os posts que abordaram exclusivamente o confronto ocorrido entre a Polícia Militar e os servidores públicos; "manifestação" envolveu as matérias que focavam na agenda da greve, como as passeatas e demais atividades que envolviam o movimento; em "votações" foram categorizadas as notícias sobre as votações da Assembleia Legislativa sobre a pauta de reivindicação; os "efeitos sociais da greve" referemse aos assuntos que englobavam calendário de reposição de aula, corte de serviços prestados à comunidade, entre outros; e aquelas notícias que não cabiam em nenhuma da categorias anteriores foram coletadas como "outro". 
Em relação às curtidas, a maior média se encontra no tema "confronto" também, com 2.452 curtidas, sendo que o número máximo neste tema chegou a mais de 15 mil, como é o caso da publicação* "Cenas de violência no Centro Cívico". ${ }^{13}$ Já sobre os compartilhamentos, a maior média também é para os posts sobre o confronto, sendo que o reverso são as postagens sobre efeitos sociais da greve, com menos de 600 . No caso do confronto, os compartilhamentos passaram de 60 mil. A tabela segue abaixo:

Tabela 3 - Dados descritivos da média de interação para cada tema específico

\begin{tabular}{|c|c|c|c|c|c|c|}
\hline & & $\mathrm{N}$ & Média & $\begin{array}{l}\text { Desvio } \\
\text { Padrão }\end{array}$ & Mínimo & Máximo \\
\hline \multirow[t]{7}{*}{ Comentários } & Negociações & 22 & 283,18 & 251,201 & 12 & 1027 \\
\hline & Confronto & 42 & 440,62 & 583,289 & 28 & 3497 \\
\hline & Manifestação & 27 & 231,81 & 115,876 & 39 & 499 \\
\hline & Votações & 21 & 182,62 & 182,604 & 15 & 673 \\
\hline & Efeitos sociais da greve & 12 & 266,08 & 214,542 & 1 & 632 \\
\hline & Outro & 8 & 339,38 & 393,962 & 42 & 1124 \\
\hline & Total & 132 & 308,62 & 382,350 & 1 & 3497 \\
\hline \multirow[t]{7}{*}{ Curtidas } & Negociações & 22 & 1262,32 & 1967,022 & 153 & 8616 \\
\hline & Confronto & 42 & 2452,43 & 3515,106 & 167 & 15935 \\
\hline & Manifestação & 27 & 2054,85 & 1828,366 & 372 & 8924 \\
\hline & Votações & 21 & 1137,48 & 1415,242 & 103 & 5058 \\
\hline & Efeitos sociais da greve & 12 & 820,42 & 429,239 & 86 & 1401 \\
\hline & Outro & 8 & 1762,63 & 2794,675 & 101 & 8590 \\
\hline & Total & 132 & 1773,39 & 2499,102 & 86 & 15935 \\
\hline \multirow{7}{*}{$\begin{array}{l}\text { Compartilha- } \\
\text { mentos }\end{array}$} & Negociações & 22 & 554,32 & 704,147 & 49 & 2990 \\
\hline & Confronto & 42 & 3612,67 & 11253,314 & 1 & 67846 \\
\hline & Manifestação & 27 & 634,04 & 791,409 & 51 & 3924 \\
\hline & Votações & 21 & 1259,48 & 2320,613 & 41 & 7963 \\
\hline & Efeitos sociais da greve & 12 & 281,75 & 179,417 & 10 & 591 \\
\hline & Outro & 8 & 728,88 & 1018,230 & 50 & 3162 \\
\hline & Total & 132 & 1641,72 & 6528,065 & 1 & 67846 \\
\hline
\end{tabular}

Fonte: Autoras (2015)

Até então notam-se médias maiores e menores em relação às três formas de interação pelo Facebook, com alguns destaques, tais como aqueles citados acima. No entanto, não se sabe se esses valores são significativos, usando o limite crítico de 0,000 e confiança de $95 \%$. O objetivo então, usando o teste ANOVA de comparação de médias para grupos com três ou mais categorias, é

13 Fanpage da Gazeta do Povo. "Atualização: Segundo a Prefeitura de Curitiba, 213 pessoas ficaram feridas nas manifestações (...)". 29 abr. 2015 
chegar a conclusão se tais diferenças podem ser generalizadas. Abaixo têm-se os resultados no que diz respeito às categorias dentro da variável "tema" e as diferenças entre elas.

Tabela 4 - Teste ANOVA comparando grupos dentro do tema "greve"

\begin{tabular}{|l|l|r|r|}
\hline \multicolumn{2}{|c|}{ ANOVA } & \multicolumn{1}{c|}{ F } & \multicolumn{1}{c|}{ Sig. } \\
\hline Comentários & Entre Grupos & 1,787 & 0,120 \\
\hline Curtidas & Entre Grupos & 1,523 & 0,187 \\
\hline Compartilhamentos & Entre Grupos & 1,174 & 0,326 \\
\hline
\end{tabular}

Fonte: Autoras (2015)

O teste ANOVA indica que não se pode generalizar tal resultado quanto às diferenças nas médias de comentários, compartilhamentos e curtidas nos subtemas dentro do grande leque sobre a greve, o que refuta a segunda hipótese apresentada. A relação entre as categorias para cada tipo de interação não é significativa em nenhum dos casos, com todos os resultados acima do limite crítico de 0,000. Isso indica que o tema "greve" é capaz de mobilizar os leitores e chamar a atenção, tendo médias significativamente diferentes para os três tipos de interação em relação aos posts sobre outros temas, mas que ao observar temas diferentes dentro do assunto "greve" as diferenças não podem ser generalizadas. Portanto, pode-se afirmar que o tema "greve" mobiliza mais o leitor que participa mais, confirmando a primeira hipótese, mas não se pode dizer o mesmo quanto aos subtemas - "efeitos", "votações", etc. - sendo que a segunda hipótese foi, então, refutada. Retomaremos os principais achados da análise a seguir.

\section{Conclusão}

Este artigo teve como principal objetivo identificar como as postagens sobre a greve dos professores do Paraná geraram interação entre os usuários e os conteúdos na página do jornal Gazeta do Povo, no Facebook. Trata-se de um estudo de caso que buscou mensurar o engajamento gerado pelos posts sobre a temática, em comparação com os conteúdos que não diziam respeito à greve. Parte-se da literatura sobre circulação e consumo de notícias nas redes (Recuero, 2009; Zago, 2013; Ferreira e Alves, 2014; Zago e Bastos, 2014) e também da vertente que classifica a rede como um espaço propenso à disponibilização de informação de maneira mais acessível e local de promoção do debate (Mendonça e Pereira, 2011; Ferreira e Alves, 2014). 
Os dados indicam que a temática greve gerou mais engajamento do que as demais - somando curtidas, comentários e compartilhamentos - , com destaque para os compartilhamentos, que foram sete vezes maiores do que referente às notícias de outras temáticas; e aos comentários, que totalizaram um número quatro vezes maior quando comparado aos demais posts. $\mathrm{O}$ alto grau de engajamento possibilita que o conteúdo chegue às sub-redes dos usuários (Recuero, 2009), tendo um impacto significativo na propagação desse conteúdo (Zago e Bastos, 2013), fazendo com que mais pessoas tenham acesso a esse tipo de informação. $O$ grande número de comentários também indica que a rede social foi usada como espaço de conversação para expor opiniões dos usuários, algo que também é identificado como possibilidade da internet por Marques (2006).

A confirmação da hipótese quanto a diferença na interação entre leitores e conteúdo nas postagens sobre a greve em relação às demais publicações corrobora com a ideia de que nem todos os temas geram interesse nos usuários, sendo que assuntos polêmicos tendem a ocasionar maior interatividade (Barros e Carreiro, 2015; Sampaio e Barros, 2010), principalmente no debate on-line por meio dos comentários, o que leva a crer que o tipo de tema deve ser lavado em conta para estudar a maneira como as pessoas se envolvem em mobilizações e interagem nas redes sociais. Não basta estar na rede para ser lido e compartilhado, por exemplo. Por outro lado, nossa segunda hipótese foi refutada, conforme demonstrado na análise. Acreditava-se que haveria diferenças significativas de engajamento dentro os subtemas referentes à greve. Porém, o que se observa é que o tema "greve" é capaz de mobilizar os leitores e chamar a atenção, tendo médias significativamente diferentes para os três tipos de interação em relação aos posts sobre outros temas, mas que ao observar subtemas dentro do assunto "greve", as diferenças não são altamente significativas e não podem ser generalizadas.

Embora este artigo se limite a verificar padrões de engajamento sobre um determinado assunto, ele indica que determinados temas tendem a impactar na maneira como o leitor se comporta na rede, sendo interessante para verificar que nem todo tema jornalístico ganha amplitude nas redes sociais, a menos que haja relação de proximidade, interesse, entre outros valoresnotícias imbricados (Harcup e O'Neill, 2001). Por fim, os dados indicam que as redes sociais foram fundamentais para a circularidade de conteúdo (Zago, 2012) sobre a greve durante o período, o que é constatado pelo alto número de curtidas e compartilhamentos e contribui para pensar a convergência e migração de mídias tradicionais para a internet. Espera-se, ainda, que esta pesquisa - dedicada somente a um estudo de caso - incite estudos futuros 
que busquem identificar diferenças de engajamento dos leitores a partir de temáticas diferentes em contextos menos específicos para ver em que medida esses achados e argumentos se sustentam, assim como a verificar, em termos quanti-qualitativos, o conteúdo dessas interações, seguindo os estudos na perspectiva da deliberação on-line.

\section{Referências}

AGGIO, Camilo. Campanhas On-line: o percurso de formação das questões, problemas e configurações a partir da literatura produzida entre 1992 e 2009. Opinião Pública, Campinas, v. 16, n. 2, p.426-445, nov. 2010. Disponível em: <http://www. scielo.br/scielo.php?script=sci arttext\&pid=S0104-62762010000200006\&lng $=$ en\&nrm=iso >. Acesso em: 4 nov. 2015.

; REIS, Lucas. Campanha eleitoral no Facebook: usos, configurações e o papel atribuído por três candidatos eleitos nas eleições municipais de 2012. In: ALDÉ, Alessandra; MARQUES, Francisco Paulo Jamil. Internet e Poder local. Salvador: Edufba, 2015.

BARROS, Samuel; CARREIRO, Rodrigo. A discussão pública e as redes sociais on-line: o comentário de notícias no Facebook. Revista Fronteiras, Porto Alegre, v. 17, n. 2, p. 174-185, mai/ago. 2015. Disponível em: <http://www.revistas.unisinos.br/ index.php/fronteiras/article/view/fem.2015.172.05/4732>. Acesso em: 2 nov. 2015.

BARTHEL, Michael e outros. The Evolving Role of News on Twitter and Facebook. In: Journalism.org, 2015.Disponívelem:<http://www.journalism.org/2015/07/14/ the-evolving-role-of-news-on-twitter-and-facebook>. Acesso em: 17 jul. 2015.

BRASIL. Presidência da República. Secretaria de Comunicação Social. Pesquisa Brasileira de Mídia 2015: hábitos de consumo de mídia pela população brasileira. Brasília: Secom, 2014. Disponível em: <http://www.secom.gov. br/atuacao/pesquisa/lista-de-pesquisas-quantitativas-e-qualitativas-decontratos-atuais/pesquisa-brasileira-de-midia-pbm-2015.pdf>. Acesso em: 23 dez. 2014.

CANAVILHAS, João. Webjornalismo: da pirâmide invertida à pirâmide deitada. BOCC Biblioteca On-line de Ciências da Comunicação, 2006. Disponível em: < http:// www.bocc.ubi.pt/pag/canavilhas-joao-webjornalismo-piramide-invertida. pdf>. Acesso em: 5 jul. 2015.

DALMASO, Silvana. Usos do Facebook na publicação de conteúdo jornalístico: um estudo inicial das postagens do Jornal A Razão. In: 10. Encontro Nacional de Pesquisadores em Jornalismo, 2012, Curitiba. Anais do $\mathbf{1 0}^{\circ}$ Encontro Nacional de Pesquisadores em Jornalismo. Curitiba: PUCPR, 2012. p. 1-14 
FERREIRA, Luciana Gomes; ALVES, Anabela Gradim. Comunicação e Sociabilidade na Cibercultura a partir do consumo, apropriação, produção e recirculação de notícias locais nas redes sociais on-line. In: PINTO-COELHO, Zara; ZAGALO, Nelson. Comunicação e Cultura. III JORNADAS DOUTORAIS, CIÊNCIAS DA COMUNICAÇÃO E ESTUDOS CULTURAIS. Braga: Centro de Estudos de Comunicação e Sociedade, p. 89-103, 2014.

GADINI, Sergio. (org). Coberturas jornalísticas (de)marcadas: a greve dos professores na mídia paranaense em 2015. Ponta Grossa: Estúdio Texto, 2015.

HEINRICH, Ansgard. Network Journalism: Journalistic Practice in Interactive Spheres. Routledge, 2011.

HARCUP, Tony; O"NEILL, Deirdre. What Is News? Galtung and Ruge revisited. Journalism Studies, v. 2, n. 2, p. 261-280, 2001.

KLOTZ, Robert. J. Internet Campaigning for Grassroots and Astroturf Support. Social Science Computer Review, v. 25, n. 01, p. 3-12, 2007.

MAIA, Rousiley. Democracia e internet como esfera pública virtual: aproximando as condições do discurso e da deliberação. In: X Compós, 2001, Brasília. Anais do X Encontro Anual da Compós. Brasília, UnB, 2008. Disponível em: <http://www. compos.org.br/data/biblioteca 1252.pdf>. Acesso em: 2 nov. 2015.

MARQUES, Francisco Paulo Jamil Almeida. Debates políticos na internet: a perspectiva da conversação civil. Opinião Pública, Campinas, v. 12, n. 1, p. 164-187, abr/ mai. 2006. Disponível em: <http://www.scielo.br/pdf/op/v12n1/29402.pdf>. Acesso em: 2 nov. 2015.

MENDONÇA, Ricardo Fabrino; PEREIRA, Marcus Abílio. Democracia digital e deliberação on-line: um estudo de caso sobre o VotenaWeb. IV Congresso Latino Americano de Opinião Pública (WAPOR), Belo Horizonte, 2011. Anais do IV Congresso Latino Americano de Opinião Pública (WAPOR). Belo Horizonte, UFMG, 2011. Disponível em: <https://www.ufmg.br/on-line/arquivos/anexos/Ricardo.pdf >. Acesso em: 2 nov. 2015.

MONTARDO, Sandra Portella; ARAÚJO, Willian. Performance e práticas de consumo online: ciberativismo em sites de redes sociais. Revista FAMECOS, Porto Alegre, v. 20, n. 2, p. 472-494, mai/ago 2013. Disponível em: <http://revistaseletronicas. pucrs.br/ojs/index.php/revistafamecos/article/view/13078/10020>. Acesso em: 2 nov. 2015.

PRIMO, Alex. Transformações do jornalismo em rede: sobre pessoas comuns, jornalistas e organizações; blogs, Twitter, Facebook e Flipboard. Intexto, Porto Alegre, v. 2, n. 25, p. 130-146, dez 2011. Disponível em: <http://seer.ufrgs.br/intexto/article/ viewFile/24309/14486>. Acesso em: 10 ago. 2015.

RECUERO, Raquel. Redes sociais na internet. Porto Alegre: Sulina, 2009. 
SAMPAIO, Rafael; BARROS, Samuel. Deliberação no jornalismo on-line: um estudo dos comentários do Folha.com. In: Intexto. Porto Alegre, v. 2, n. 23 p. 183- 202, jul/ dez 2010.

TEIXEIRA, Mabel Oliveira. A interação usuário x jornal em um site de rede social: indícios de uma mudança. Brazilian Journalism Research, v. 10, n. 1, 2014.

ZAGO, Gabriela. Da circulação à recirculação jornalística: filtro e comentário de notícias por interagentes no Twitter. In: XXI Compós, 2012, Juiz de Fora. Anais do XXI Encontro Anual da Compós. Juiz de Fora, UFJF, 2012.

; BASTOS, M. Visibilidade de notícias no Twitter e no Facebook: análise comparativa das notícias mais repercutidas na Europa e nas Américas. Brazilian Journalism Research, v. 9, n. 1, p. 116-133, 2013. Disponível em: < http://bjr. sbpjor.org.br/bjr/article/view/510/445>. Acesso em: 20 ago. 2015.

ZÚÑIGA, Homero Gil. e outros . Digital democracy: reimagining pathways to political participation. Journal of Information Technology \& Politics, v. 7, n. 1, p. 36-51, fev 2010.

Recebido em: 4/11/2015

Aceito em: 23/11/2015

Endereço Autoras:

Michele Goulart Massuchin <mimassuchin@gmail.com $>$

R. Urbano Santos, s/n - Centro

Imperatriz, MA - Brasil

CEP 65900-410

Camilla Quesada Tavares <camilla.tavares8@gmail.com>

R. Urbano Santos, $\mathrm{s} / \mathrm{n}$ - Centro

Imperatriz, MA - Brasil

CEP 65900-410 